\title{
43. UNDERWAY GEOPHYSICAL DATA, DEEP SEA DRILLING PROJECT LEG 58, FROM YOKOHAMA, JAPAN, TO NAHA, OKINAWA, IN THE NORTH PHILIPPINE SEA
}

\author{
Kazuo Kobayashi, Ocean Research Institute, University of Tokyo
}

\begin{abstract}
Seismic-reflection (air-gun, single-channel recording) total-magnetic-force (proton magnetometer), and bottom-topography $(12-\mathrm{kHz}$ and $3.5-\mathrm{kHz}$ echo-sounder) profiles were continuously recorded on board the Glomar Challenger, cruising between a port of call and a site as well as between two adjacent sites. An index chart shows positions of observation on a newly prepared bathymetric map of the Shikoku Basin (Figure 1). An index chart for the Daito Ridge area is given in Figure 2. Continuous reflection profiles in five segments (Figure 3 ) is presented as a foldout in the back pocket.
\end{abstract}

Segment 1 in Figure 3 illustrates a profile from the western flank of the Shichito-Iwo Jima Ridge to the eastern margin of the Shikoku Basin, in which thick sediment layers in the flank of the ridge which thin toward the margin of the basin can be seen. Several reflectors, which are possibly the turbidite layers, can be identified in the thick sediment in the flank area (see Klein and Kobayashi, this volume).

Segment 2 is a profile between Sites 442 and 443 , crossing the northeastern half of the Shikoku Basin. Sedimentary environments of Sites 442 and 443 can be well compared and correlated in this profile. Segment 3 shows a complete traverse of the Shikoku Basin from Site 444 westward, south of Sites 442 and 443 . At this latitude, sediment cover is generally thinner than at the two sites.

Segment 4 illustrates a reflection profile along the southern flank of the Daito Ridge. In the basin south of the ridge, sediment is generally flat and semi-stratified, as seen at Site 446. The inner wall of the Ryukyu Trench is very rugged, with complex sediment structure, although the record is somewhat obscure.

Segment 5 indicates the record of a $3.5-\mathrm{kHz}$ echo sounder at the crest of the Daito Ridge. Topography is flat at the top. Sediment is thicker in the northern margin than in the south ( 50 meters thick). The subbottom reflector is more rugged than the surface. This sedimentary structure, combined with the multichannel records (IPOD-Japan, 1978) implies that the subbottom reflector is an eroded surface covered with Holocene foraminifer ooze.

Figure 4 provides profiles of magnetic anomalies and water depth as the output display of the DSDP computer file. Figure $4 \mathrm{a}$ is a profile from Yokohama to Site 444 in which the eastern margin of the Shikoku Basin is clearly seen. It is to be noted that the amplitude of magnetic anomalies is very large on the Izu Shichito-Iwo Jima Ridge, probably because of highly magnetized igneous bodies composing the volcanic islands and seamounts, small in the slope of the ridge and intermediate but detectable in the basin.

Figure $4 \mathrm{~b}$ is a composite profile from Site 444 to the north Philippine Basin east of the Ryukyu Trench. The amplitude of magnetic anomalies on the Kyushu-Palau Ridge appears to be small, unless affected by topography. Magnetic anomalies seem to be higher in the north basin than the south basin of the Daito Ridge (see the center of the figure). Magnetic anomalies upon the Daito Ridge appear to originate from nearly horizontal magnetization of the Daito Ridge (see Site 446 report, this volume).

Magnetic anomalies associated with the Ryukyu Trench appear to be small (Figure 4C). The origin of the anomaly on the outer swell east of the trench is unknown, but it might be related to buried igneous material.

\section{REFERENCE}

IPOD-Japan, 1978. Multi-channel seismic reflection data across the Shikoku Basin and the Daito Ridges, 1976, part 1. IPOD-Japan Basic Data Series, No. 2. 


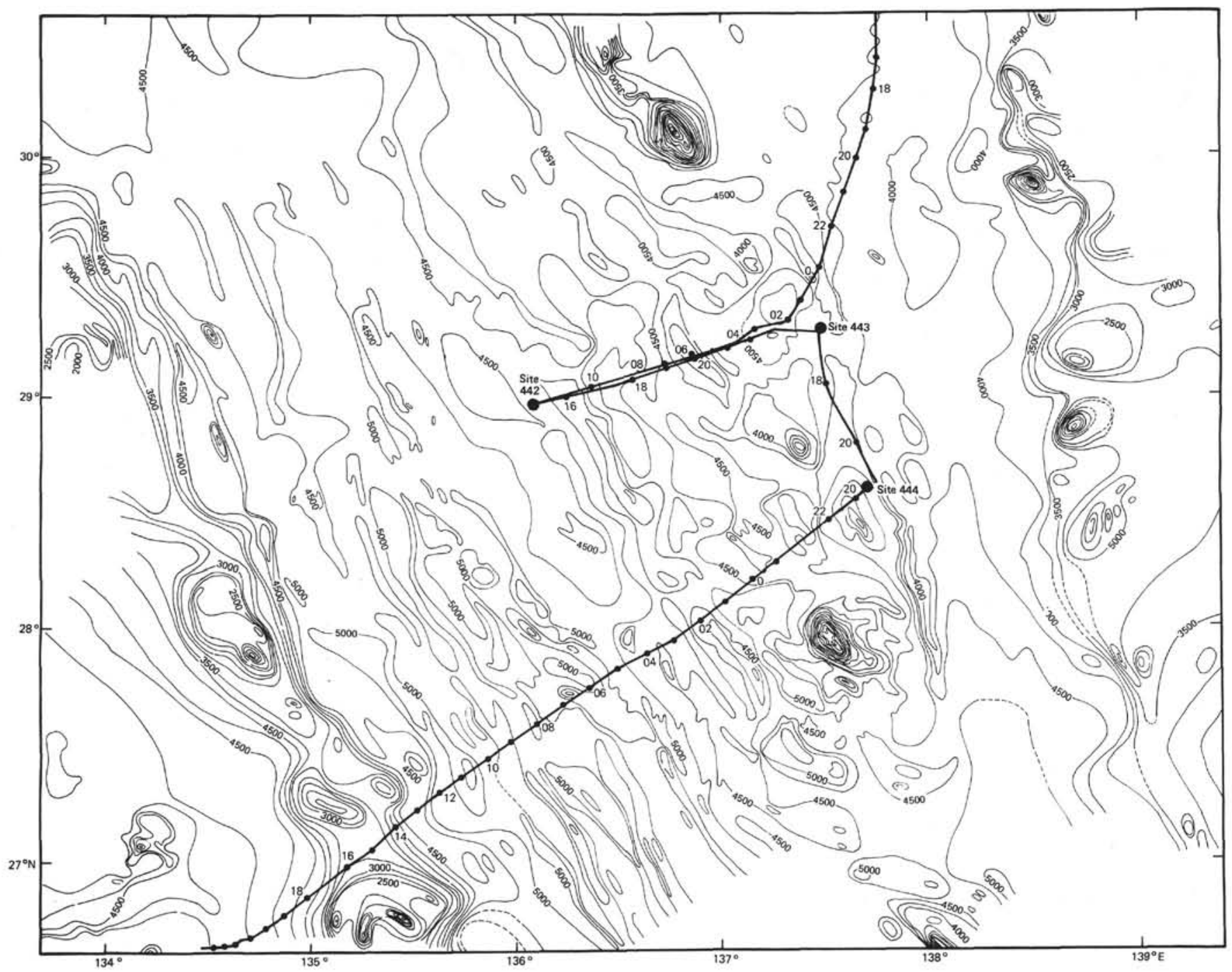

Figure 1. Location of drill sites and ship's positions plotted on a detailed bathymetric chart prepared for site selection, based upon site survey and data compilation. Numbers beside the circles indicate GMT for the positions of the Glomar Challenger. Contour interval 250 meters. Contours denote depths at 100-meter intervals. 


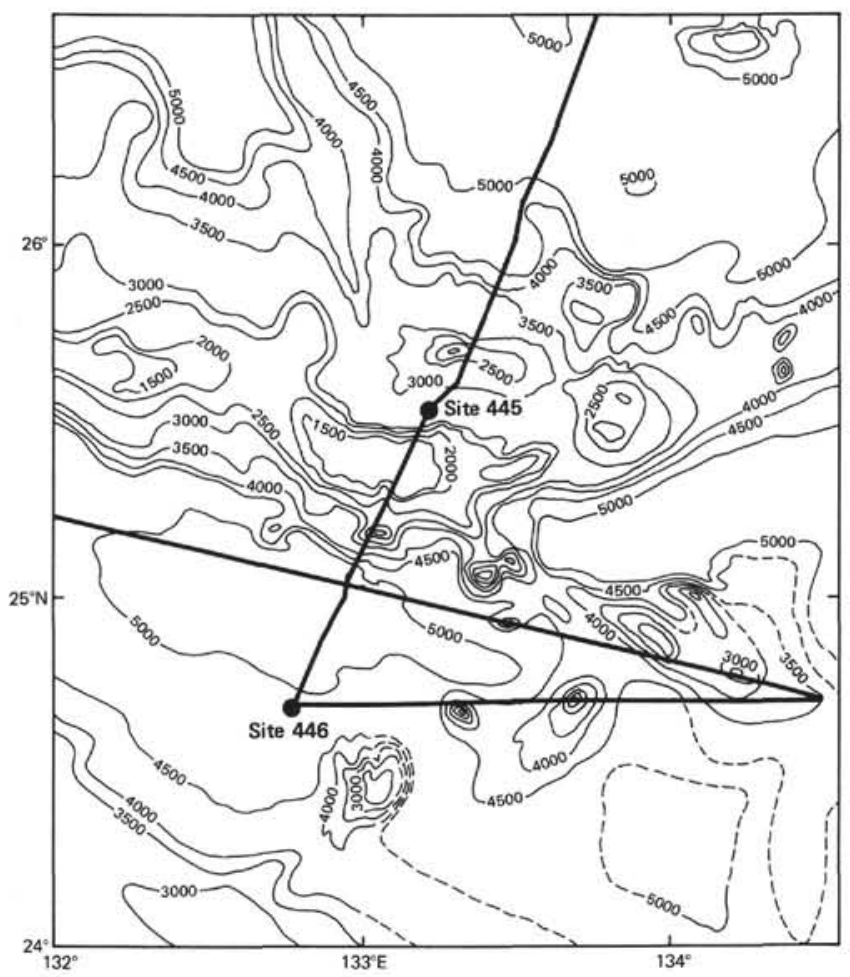

Figure 2. Location of drill sites and ship's position plotted on a detailed bathymetric chart (Tokuyama, this volume). Numbers beside the circles indicate GMT for the positions of the Glomar Challenger. Contour interval 500 meters. Mercator projection. 
N. MILES
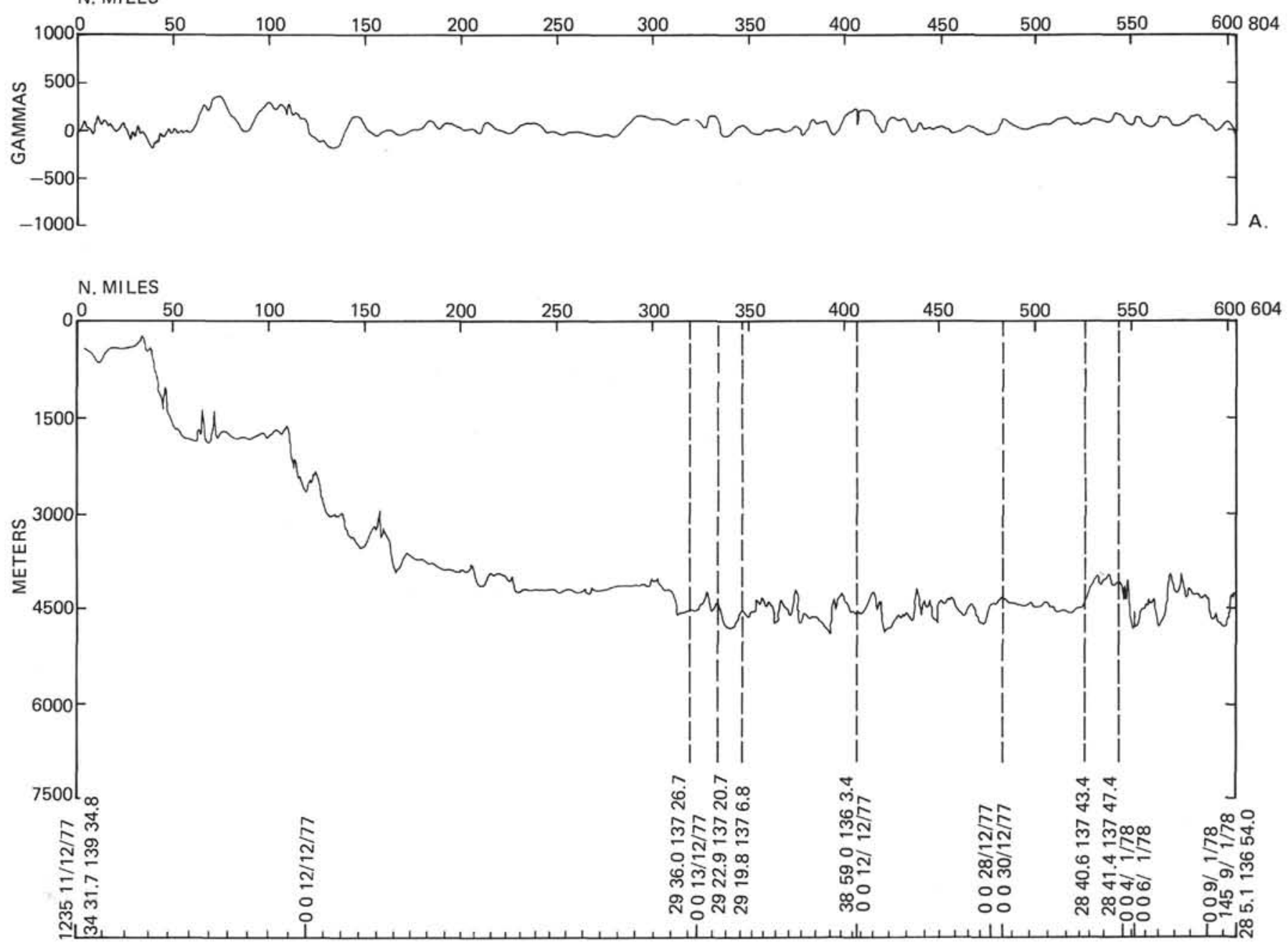

Figure 4. Profiles of magnetic anomalies and water depths obtained by Glomar Challenger during Leg 58. A. Yokohama to Site 444. B. Site 444 to the north Philippine Basin east of the Ryukyu Trench. C. The Ryukyu Trench to Naha, Okinawa. 

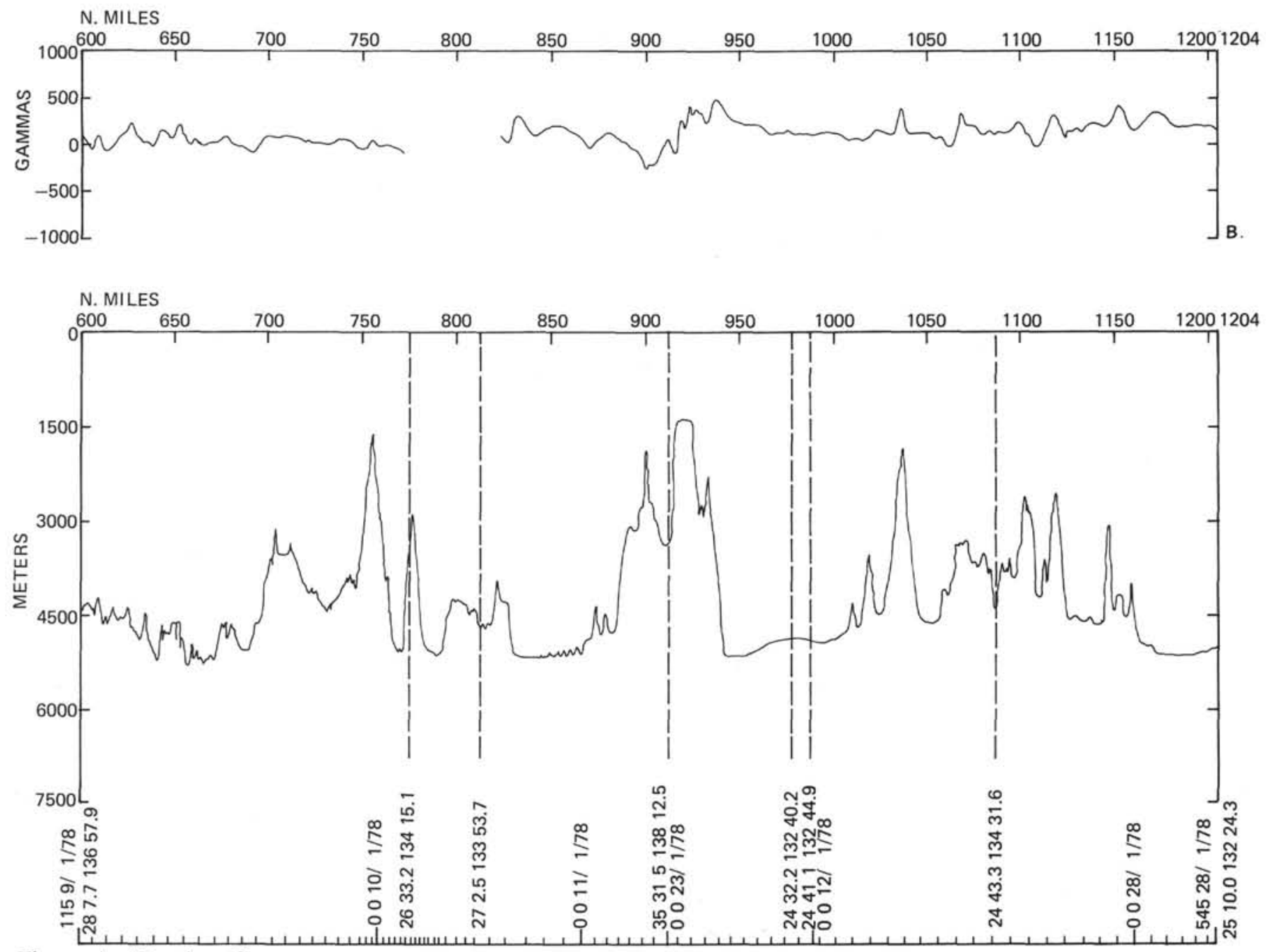

Figure 4. (Continued). 

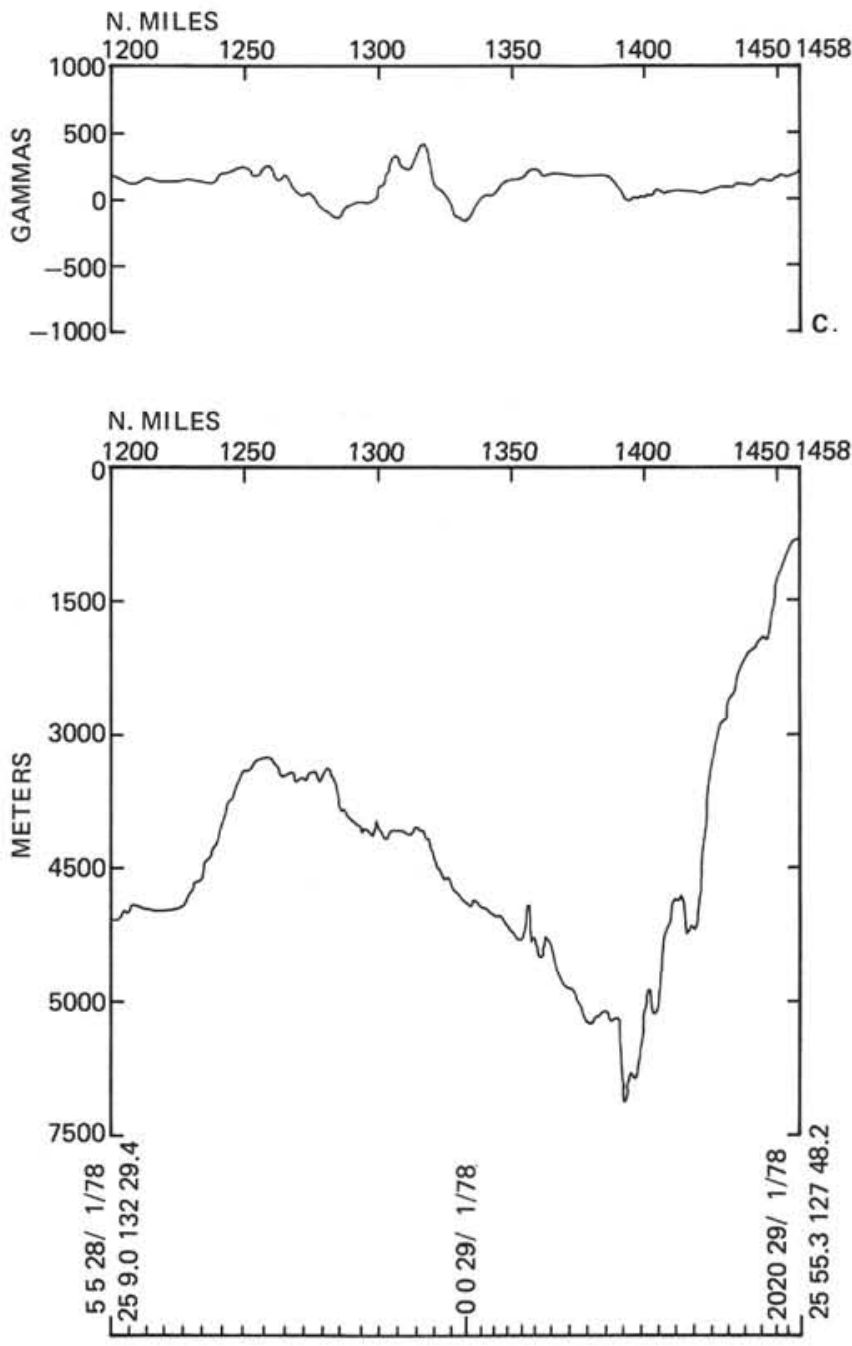

Figure 4. (Continued). 